14,13

\title{
Фотофизические свойства тонких пленок перилена, модифицированного функциональными группами диангидрида и диимида тетракарбоновой кислоты
}

\author{
(C) А.С. Комолов ${ }^{1}$, Э.Ф. Лазнева ${ }^{1}$, Е.В. Жижин ${ }^{1}$, Э.К. Алиджанов ${ }^{2}$, Ю.Д. Лантух ${ }^{2}$, \\ С.Н. Летута ${ }^{2}$, Д.А. Раздобреев ${ }^{2}$
}

${ }^{1}$ Санкт-Петербургский государственный университет, Санкт-Петербург, Россия

${ }^{2}$ Оренбургский государственный университет,

Оренбург, Россия

E-mail: a.komolov@spbu.ru

Поступила в Редакцию 19 апреля 2021 г.

В окончательной редакции 19 апреля 2021 г.

Принятатк публикации 26 апреля 2021 г.

\begin{abstract}
Методом атомно-силовой микроскопии исследована морфология пленок органических полупроводников диангидрида перилентетракарбоновой кислоты (PTCDA) и дибензил-диимида перилентетракарбоновой кислоты (N, N'-DBPTCDI) сформированных вакуумным термическим напылением. Показано, что отжиг пленок при $420 \mathrm{~K}$ приводит к перестройке их структуры и кристаллизации. На основе полученных спектров оптического поглощения исследуемых пленок оценена оптическая ширина запрещенной зоны. Установлена температурная зависимость темновой проводимости пленок PTCDA и N, N-DBPTCDI до и после отжига $(T=420 \mathrm{~K})$. Определены значения энергии активации ловушек носителей заряда. Проведено моделирование структуры плотности локализованных в запрещенной зоне состояний исследуемых пленок по спектрам фотопроводимости в режиме постоянного фототока. Сформированы модельные фотовольтаические ячейки на основе PTCDA/CuPc и N, N-DBPTCDI/CuPc-структур. Измерена кинетика затухания вентильной фотоэдс фотовольтаических ячеек при импульсном световом возбуждении. На основе выполненных измерений дана оценка подвижности носителей заряда в исследуемых полупроводниковых материалах.
\end{abstract}

Ключевые слова: сопряженные органические молекулы, производные перилена, тонкие пленки, фотоэлектрические свойства, температурная зависимость электропроводности, подвижность носителей заряда.

DOI: 10.21883/FTT.2021.09.51281.091

\section{1. Введение}

Изучение фотофизических характеристик органических материалов перспективно в плане разработки новых фотовольтаических устройств. Одним из преимуществ органических материалов является возможность настраивать оптические и электрофизические свойства путем модификации структуры как отдельных молекул, так и материала в целом [1-3]. Модификацию электронных свойств тонкопленочных органических материалов можно проводить путем воздействия со стороны поверхности металлической или полупроводниковой подложки $[4,5]$ и путем введения в состав органических молекул электроактивных функциональных групп, таких как карбоксильные, азотосодержащие, фторосодержащие [68]. Для создания эффективных элементов органических фотовольтаических ячеек, светодиодов важно выбрать подходящую донорно-акцепторную пару, обеспечивающую высокую степень разделения зарядов. Электронноакцепторные материалы, такие как производные фуллеренов, тетрацианохинодиметан характеризуются хорошими электронно-акцепторными и транспортными свойствами [9]. Однако эти материалы обладают низким коэффициентом поглощения света в видимой и ближней ИК-области. Использование в органических солнечных элементах материалов $n$-типа на основе диимид замещенного перилена привлекательно из-за их высокого молярного коэффициента экстинкции в сочетании с хорошими электронно-транспортными свойствами. Кроме того, $\pi$ - $\pi$-стэкинг в этих системах способствует эффективному межмолекулярному переносу заряда, и $\boldsymbol{\pi}-\boldsymbol{\pi}$ взаимодействия являются важным фактором процесса молекулярной самосборки [10,11].

В настоящей работе приведены результаты сравнительного исследования оптических, электронных, и структурных свойств тонких пленок, сформированных из полиароматических соединений диангидрида перилентетракарбоновой кислоты (3,4,9,10-perylenetetracarboxylic acid dianhydride, PTCDA) и дибензилдиимид-перилентетракарбоновой кислоты (N, N'-dibenzyl-perylene-tetracarboxylic acid diimide, N, N'-DBPTCDI). PTCDA широко используется в качестве электронно-акцепторного материала в устройствах молекулярной электроники, и его свойства достаточно хорошо изучены [12]. N, N-DBPTCDI привлекает интерес как одна из перспективных модификаций молекулы PTCDA (рис. 1). 


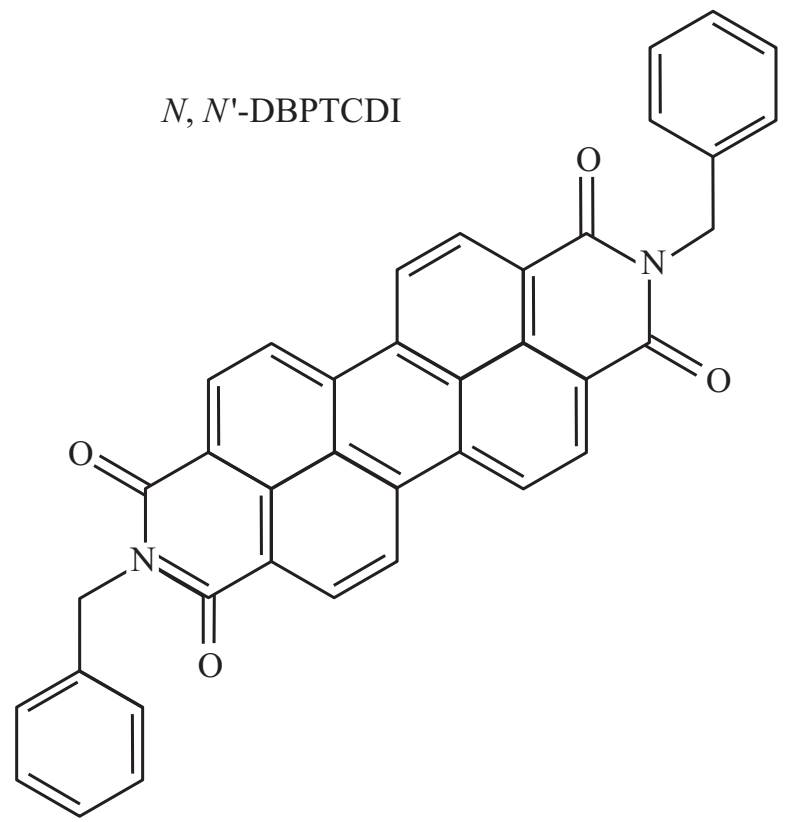

PTCDA

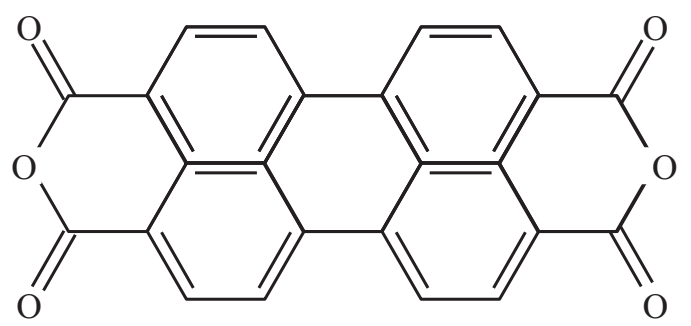

Рис. 1. Молекулярная структура исследуемых соединений.

\section{2. Эксперимент}

Пленки исследованных материалов, PTCDA и $\mathrm{N}, \mathrm{N}^{\prime}$-DBPTCDI, толщиной порядка $1 \mu \mathrm{m}$, формировали путем вакуумного напыления органического вещества при давлении $10^{-5} \mathrm{~Pa}$ из ячейки Кнудсена на поверхность кварцевого стекла со скоростью 2-3 nm/min. Температура ячейки испарителя составляла $600 \mathrm{~K}$, что обеспечивало испарение органических молекул без нарушения их стехиометрии [9]. Температуру подложки поддерживали на уровне комнатной. Толщину пленки контролировали интерференционным методом in situ. Подложки из кварцевого стекла предварительно промывали в ацетоне, спирте и кипятили в дистиллированной воде. Диагностику атомного состава сформированных пленок проводили методом рентгеновской фотоэлектронной спектроскопии (XPS). Для этого использовали комплексный фотоэлектронный спектрометр Escalab 250Xi (Thermo Fisher Scientific Inc.). Исследования проводили в условиях сверхвысокого вакуума порядка $10^{-7} \mathrm{~Pa}$ при комнатной температуре. В случае использования системы компенсации заряда парциальное давление аргона в аналитической камере составляло $10^{-5} \mathrm{~Pa}$. Энергия возбуждающих фотонов составляла $1486.6 \mathrm{eV}$, спектры остовных уровней были измерены при энергии пропускания анализатора $20 \mathrm{eV}$. При анализе измеренных XPSспектров использовали библиотеку стандартных XPSспектров производителя оборудования (Thermo Fisher Scientific Inc.), включающую атомные факторы чувствительности регистрации сигнала. Диагностика атомного состава методом XPS была направлена на установление относительных концентраций основных атомных компонент пленок PTCDA и N, N'-DBPTCDI, то есть атомов C, O и N. C целью устранения возможных поверхностных загрязнений проводили предварительную очистку поверхности образца методом бомбардировки ионами $\mathrm{Ar}^{+}$с энергией $3 \mathrm{keV}$, что описано более подробно в работе [13]. В XPS-спектрах отчетливо наблюдались максимумы атомных компонент $\mathrm{C} 1 s, \mathrm{O} 1 s$ и $\mathrm{N} 1 s$. Измеренное соотношение концентраций атомов $\mathrm{C}:$ О составило $28: 6$ в случае пленки PTCDA. При измерениях состава пенки $\mathrm{N}, \mathrm{N}^{\prime}$-DBPTCDI соотношение концентраций атомов $\mathrm{C}: \mathrm{O}: \mathrm{N}$ составило $44: 4: 2$. Такие измеренные значения относительных атомных концентраций соответствует незначительному, примерно 10\% превышению содержания атомов С в исследованных образцах, по сравнению с химической формулой исследованных молекул (рис. 1).

Морфологию и толщину напыляемых пленок контролировали методом атомно-силовой микроскопии (АСМ) с помощью сканирующего зондового микроскопа СММ 2000Т. Для измерения темновой проводимости на кварцевой подложке $2 \times 2 \mathrm{~cm}$ методом термического напыления формировалась пленка N, N'-DBPTCDI (PTCDA) толщиной $500 \mathrm{~nm}$. Далее через маску с зазором $1 \mathrm{~mm}$ напыляли серебряные токоподводящие электроды. Образец помещали на специальный держатель, снабженный нагревателем и термопарой. Ток темновой проводимости регистрировался с помощью электрометрического усилителя при приложенном напряжении $10 \mathrm{~V}$. Спектры электронного поглощения регистрировали на спектро-флуориметре СМ 2203. Спектральные зависимости фотопроводимости органических пленок в режиме постоянного фототока (СПФ) [14] измерялись на базе кафедры полупроводников МГУ.

На основе пленок исследуемых полупроводников и пленок фталоцианина меди $(\mathrm{CuPc})$ формировали фотовольтаические ячейки $\mathrm{Au} / \mathrm{CuPc} / \mathrm{PTCDA} / \mathrm{Al}$ и $\mathrm{Au} / \mathrm{CuPc} / \mathrm{N}, \mathrm{N}^{\prime}$-DBPTCDI/Al. Для этого на поверхности кварцевого стекла, методом магнетронного напыления наносилась пленка золота прозрачностью 80\%. Затем через маску, методом термического напыления, наносились последовательно пленки донорного полупроводника $\mathrm{CuPc}$, акцепторного полупроводника PTCDA $(\mathrm{N}, \mathrm{N}-\mathrm{DBPTCDI})$ и слой алюминия. Оценка подвижности носителей заряда в исследуемых органических полупроводниках проводилась по кинетике затухания вентильной фотоэдс фотовольтаических ячеек при импульсном световом возбуждении. 
$a$
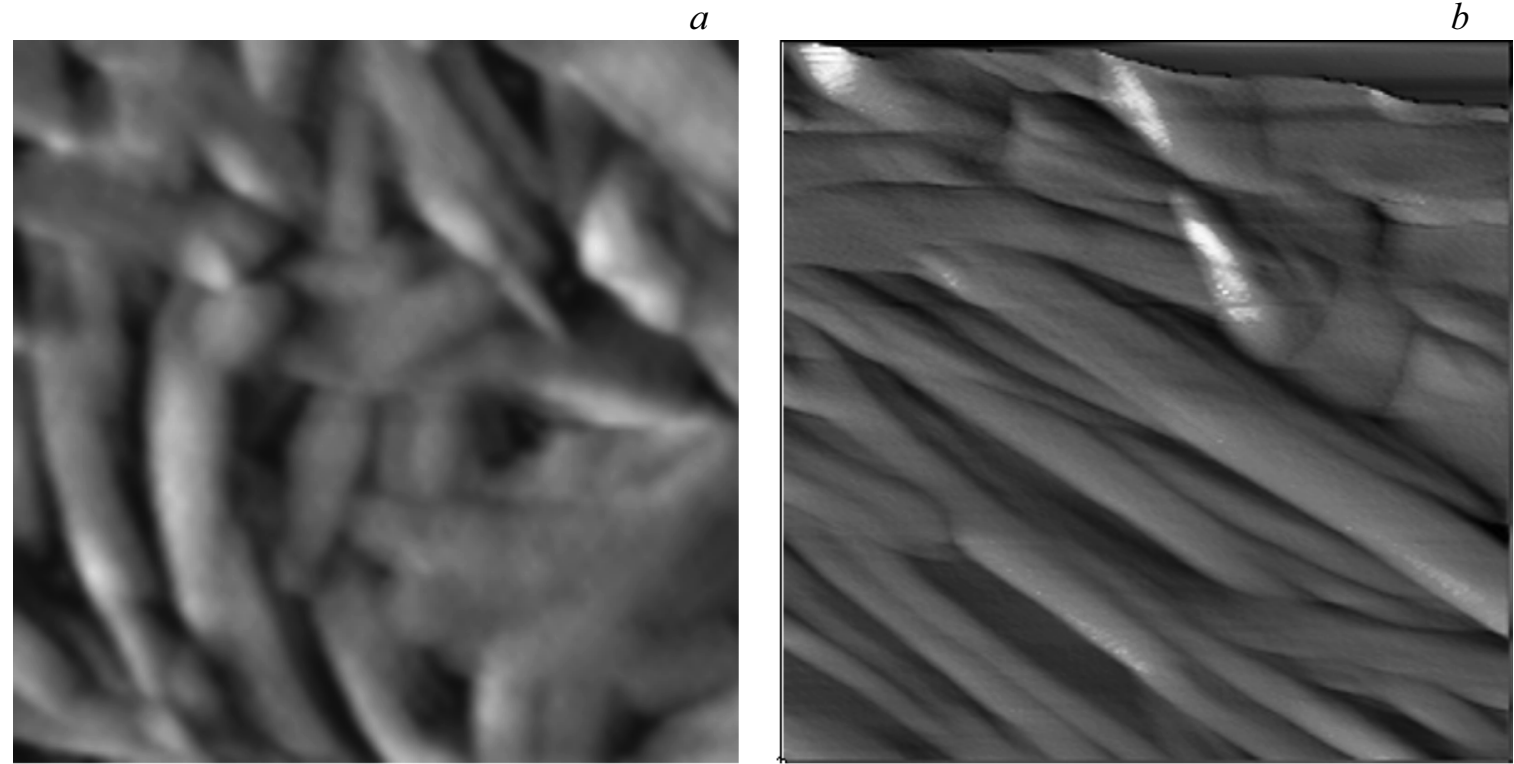

$c$
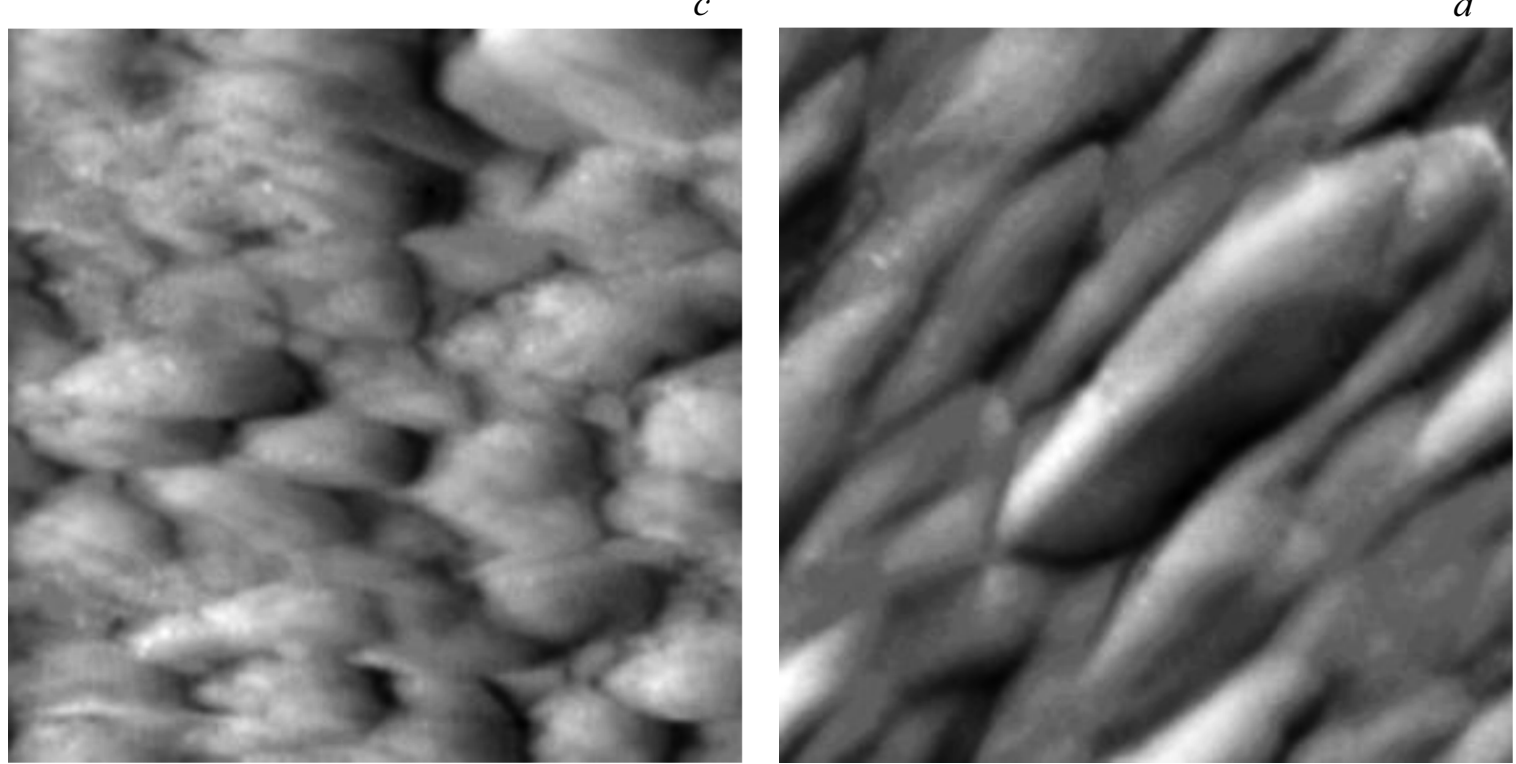

Рис. 2. АСМ-изображение $(1.5 \times 1.5 \mu \mathrm{m})$ пленки $\mathrm{N}, \mathrm{N}^{\prime} \mathrm{DBPTCDI}(a)-$ до и $(b)$ - после отжига. АСМ-изображение $(1.5 \times 1.5 \mu \mathrm{m})$ пленки PTCDA $(c)-$ до и $(d)-$ после отжига.

\section{3. Результаты и обсуждение}

На рис. 2 представлены изображения поверхности пленок исследуемых органических соединений, полученные методом атомно-силовой микроскопии. Изображения на рис. 2, $a$ и $c$ соответствуют исходным пленкам $\mathrm{N}, \mathrm{N}$-DBPTCDI и PTCDA соответственно. На рис. $2, b$ и $d$ показана морфология поверхности этих пленок в результате отжига при $420 \mathrm{~K}$ в вакууме при $10^{-5} \mathrm{~Pa}$. Видно, что отжиг пленок при температуре $420 \mathrm{~K}$ сопровождается упорядочиванием их структуры. Согласно работе [9] при температуре $420 \mathrm{~K}$ происходит кристаллизация полиароматических соединений данного типа с формированием $\pi$-л-стэкинг-структур.
На рис. 3 представлены спектры оптического поглощения пленок PTCDA и N, N-DBPTCDI. Структура спектров двух соединений идентична с учетом батохромного сдвига для N, N-DBPTCDI на $0.1 \mathrm{eV}$. Известно, что исследуемые пленки обладают достаточно высоким значением коэффициента молярной экстинкции, порядка $10^{4} \mathrm{M}^{-1} \mathrm{~cm}^{-1}$, в области 500-600 nm. Возникновение тонкой структуры и наблюдаемые максимумы объясняются возбуждением серии электронно-колебательных $\pi-\pi^{*}$-переходов и экситонных состояний [15].

Для пленок органических полупроводников характерно наличие как локализованных в запрещенной зоне электронных состояний, плотность которых экспоненциально спадает к ее середине [16], так и делокализо- 


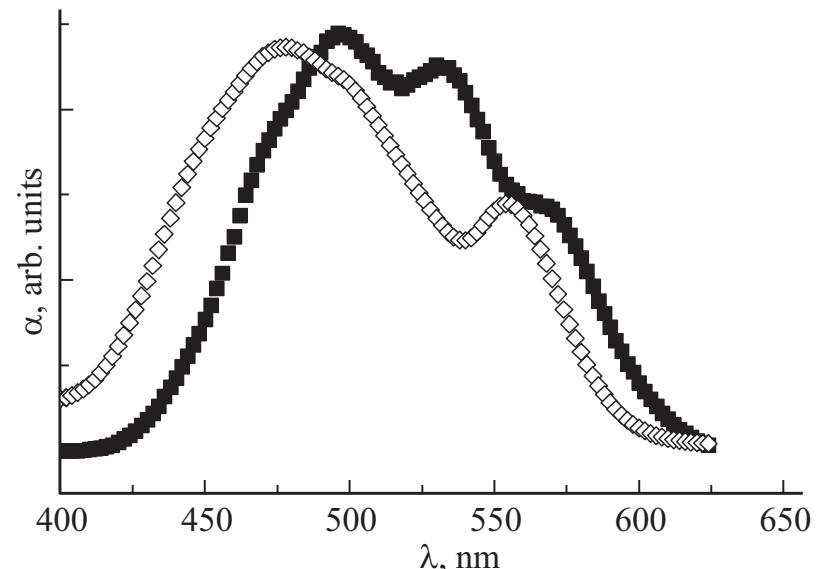

Pис. 3. Спектры оптического поглощения пленок PTCDA ( $)$ и $\mathrm{N}, \mathrm{N}$ DBPTCDI $(\mathbf{\square})$.

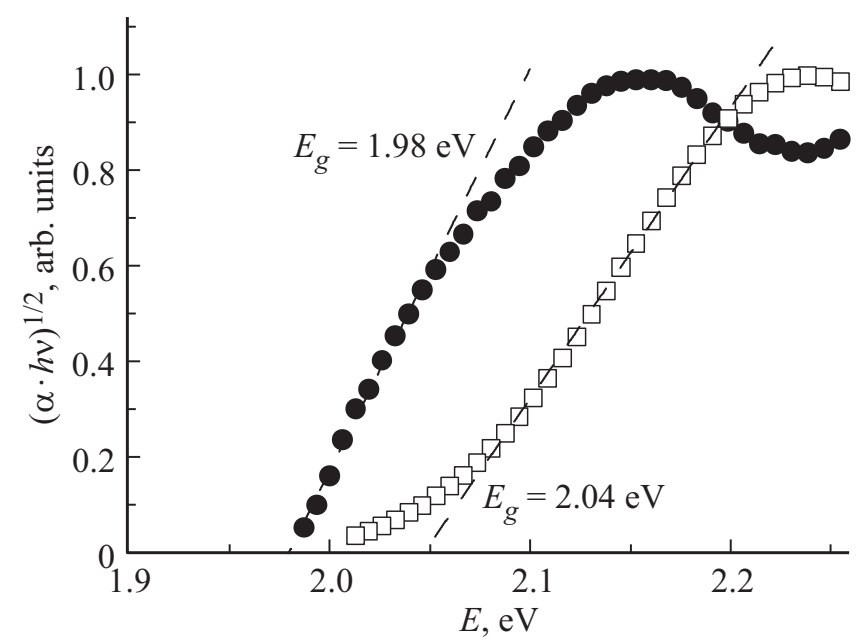

Pис. 4. Участок спектра оптического поглощения вблизи красной границы края поглощения пленок PTCDA (口) и пленок N, N-DBPTCDI (•). Пунктирные линии - аппроксимация участков экспериментально измеренных спектров для установления значений $E_{g}$ исследованных пленок.

ванных электронных состояний. Оптические переходы с участием делокализованных состояний в органических полупроводниках формируют следующий вид спектральной зависимости коэффициента поглощения $(\alpha)$ от энергии падающего кванта $(h v)$ и оптической ширины запрещенной зоны $\left(E_{g}\right)$ в области длинноволновой границы полосы поглощения [17]:

$$
\alpha \cdot h v \sim\left(h v-E_{g}\right)^{2} .
$$

Таким образом, на основе экспериментально измеренных спектров поглощения пленок PTCDA и N, N-DBPTCDI была произведена оценка $E_{g}$ этих материалов (рис. 4). Значения $E_{g}$ составили $2.04 \pm 0.2 \mathrm{eV}$ для пленки PTCDA и $1.98 \pm 0.02 \mathrm{eV}$ для пленки N, N-DBPTCDI. Полученные значения оптической ширины запрещенной зоны исследованных пленок достаточно хорошо соответствуют литературным данным, полученных методами циклической вольт-амперометрии [1] и фотоэлектронной спектроскопии [11,18]. Незначительные расхождения в установленных различными экспериментальными методами значений, а также для пленок, сформированных различными группами исследователей, могут быть обусловлены влиянием поляризационных эффектов и формированием дипольного слоя на интерфейce с подложкой $[5,19]$. Значение транспортной ширины запрещенной зоны может отличаться от ее оптической ширины на несколько десятых долей еV [19]. Так, согласно результатам работы [19] значения $E_{g}$, потенциала ионизации (IP) и сродства к электрону $\left(E_{A}\right)$ составили 2.3, 6.4 и $4.1 \mathrm{eV}$, соответственно, для пленок PTCDA. Для пленок N, N-DBPTCDI значения этих величин составили $2.3,6.3$ и $4.0 \mathrm{eV}$ соответственно.

C экспериментальной точки зрения особое внимание обычно уделяется температурной зависимости электропроводности, поскольку эта зависимость связана с механизмом транспорта заряда, а также содержит информацию о характере распределения плотности электронных состояний. В органических полупроводниках зависимость статической темновой проводимости от температуры $(T)$ имеет вид [20]:

$$
\sigma(T)=\sigma_{0} \exp \left(-\frac{E_{a}(T)}{k T}\right)^{\beta}
$$

где $k$ - постоянная Больцмана, энергия активации проводимости $\left(E_{a}\right)$ представляет собой разницу значений энергии края зоны проводимости $\left(E_{C}\right)$ и $E_{F}$, предэкспоненциальный фактор $\sigma_{0}$ зависит от базовых параметров системы, а показатель степени $\beta$ зависит от структуры материала и температурного диапазона, в котором проводятся измерения проводимости. В органических неупорядоченных материалах значение $\beta$ обычно близко к единице [20].

Транспорт носителей заряда в органических полупроводниках описывается механизмом множественного захвата ловушками [20], в которой рассматриваются только электронные переходы между локализованными состояниями в щели подвижности и делокализованными состояниями над краем подвижности. При этом большая часть носителей заряда оказываются захваченными ловушками, а перенос заряда осуществляется носителями, которые термически активируются в делокализованные состояния над краем подвижности. На рис. 5 приведены температурные зависимости проводимости пленок N, N'-DBPTCDI и PTCDA, построенные в полулогарифмическом масштабе для пленок в исходном состоянии и в состоянии после отжига при температуре $420 \mathrm{~K}$. Экспериментальные точки хорошо аппроксимируются линейными функциями, по тангенсу угла наклона которых оценена энергия активации носителей согласно формуле (1). Для N, N'-DBPTCDI исходное значение $E_{a}=0.35 \mathrm{eV}$, а после отжига $E_{a}=0.1 \mathrm{eV}$. Для 


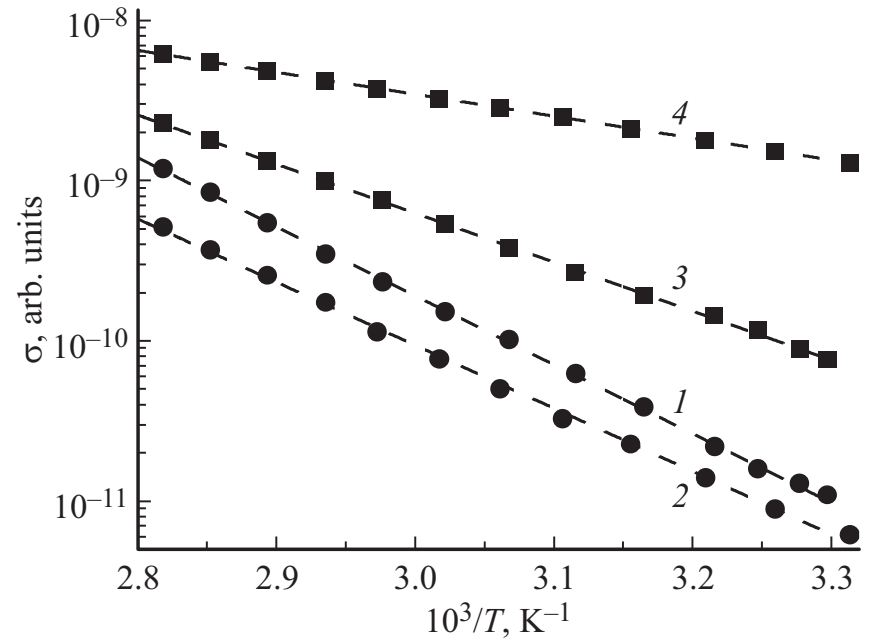

Рис. 5. Температурная зависимость темновой проводимости пленок PTCDA до (кривая 1) и после (кривая 2) отжига и пленок N, N-DBPTCDI до (кривая 3) и после (кривая 4) отжига при температуре $420 \mathrm{~K}$.

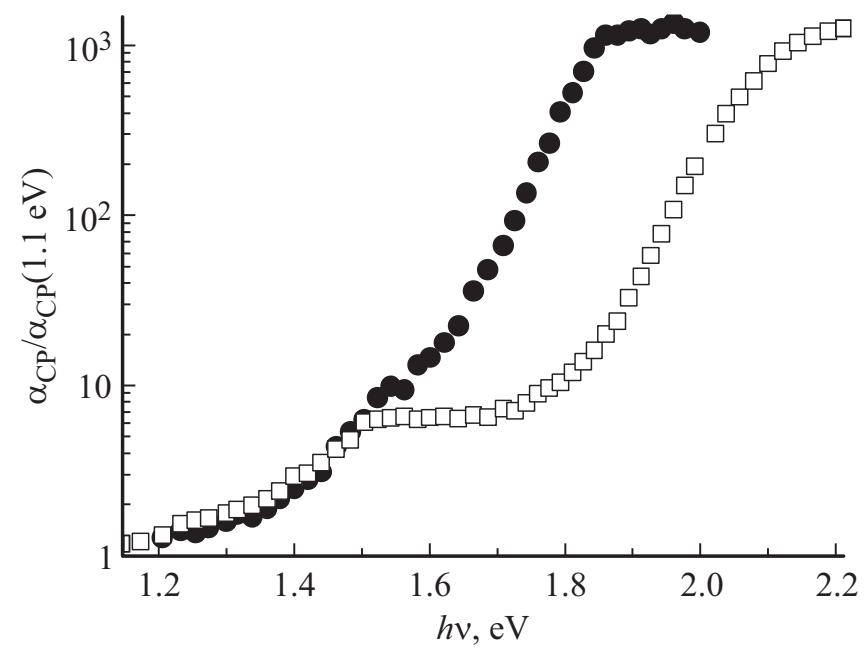

Рис. 6. Спектральные зависимости фототока постоянной величины $\alpha_{\mathrm{CP}}$, нормированные на значение $\alpha_{\mathrm{CP}}$, измеренное при $1.1 \mathrm{eV}$, для пленок N, N-DBPTCDI $(\bullet)$ и PTCDA (口).

PTCDA исходное значение $E_{a}=0.35 \mathrm{eV}$, а после отжига $E_{a}=0.25 \mathrm{eV}$. Таким образом, температурная зависимость проводимости исследованных пленок хорошо описывается выражением (1) с показателем степени $\beta$, близким по значению к 1. Изменение энергии активации после температурной обработки, вероятно, связано с процессом удаления глубоких ловушек при упорядочении структуры пленки.

На рис. 6 представлены спектры фототока через пленки N, N-DBPTCDI и PTCDA в зависимости от энергии падающего кванта, измеренные методом постоянного фототока (CP, constant phtotocurrent) [14] на краю полосы поглощения. Измеренные так спектральные зависимости $\alpha_{\text {СР }}$ охватывают значительную часть спектра локализованных в запрещенной зоне электронных состояний. Спектры СР (рис. 6) характеризуются наличием „Плеча“ в области $1.5-1.8 \mathrm{eV}$. Поскольку в данном методе измеряется интенсивность зондирующего светового потока, обеспечивающего постоянство фототока через образец, формирование особенностей зависимости $\alpha_{\mathrm{CP}}$ означает, что распределение плотности $N(E)$ локализованных электронных состояний исследованных образцов отличается от экспоненциальной зависимости. Можно

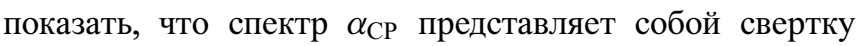
$N(E)$ в запрещенной зоне органического полупроводника и структуры плотности делокализованных состояний в зоне проводимости $g(E)$, которая пропорциональна $(h v-E)^{0.5}[21]$. Таким образом, по данным СР можно смоделировать структуру $N(E)$ путем численного проведения операции обратной свертки. Нами использовался алгоритм численного расчета $N(E)$ по спектрам СР, изложенный в работе [22]. Результаты таких расчетов для исследованных пленок N,N-DBPTCDI и PTCDA приведены на рис. 7. Нулевое значение шкалы энергий привязано к нижнему краю запрещенной зоны с учетом полученных значений ее оптической ширины. В случае пленки PTCDA (рис. 7, кружки) в области $0.5-0.6 \mathrm{eV}$ заметен максимум плотности локализованных электронных состояний на краю запрещенной зоны. Переходы из этих локализованных состояний на край зоны подвижности инициированы квантами света $h v=E_{g}-E_{l o c}$ с энергией $1.5 \mathrm{eV}$, где $E E_{l o c}$ - энергетическое положение локализованных электронных состояний относительно края запрещенной зоны.

Измерение нестационарной фотоэдс органических донорно-акцепторных систем [20,23], является эффективным инструментом изучения транспортных характеристик исследуемых органических материалов. С учетом

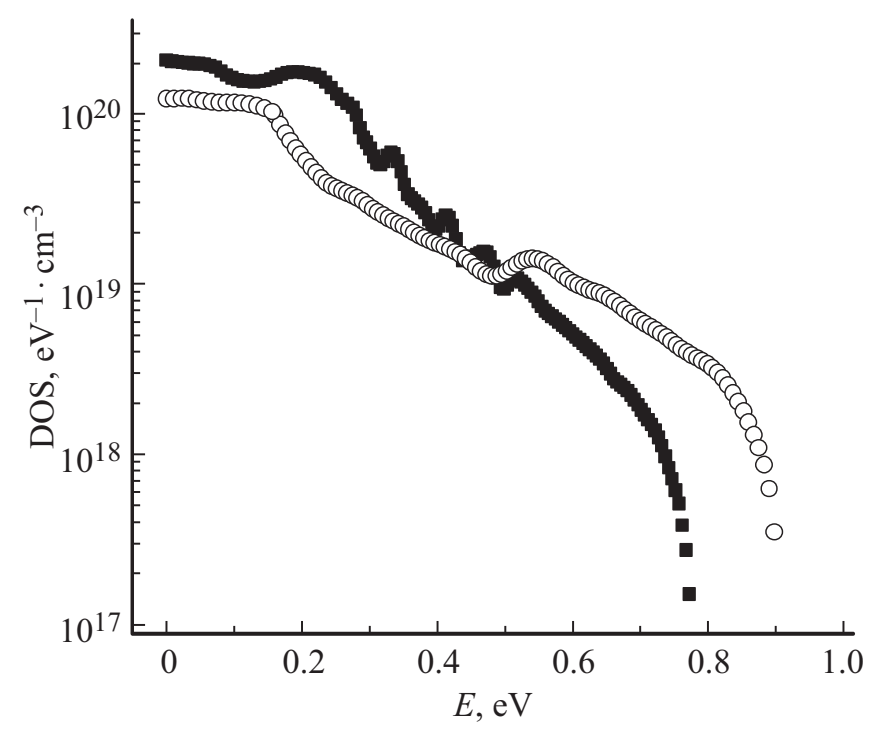

Рис. 7. Результаты расчета плотности локализованных состояний $N(E)$ в запрещенной зоне N, N-DBPTCDI (匹) и PTCDA (०) на основе спектров СР. 


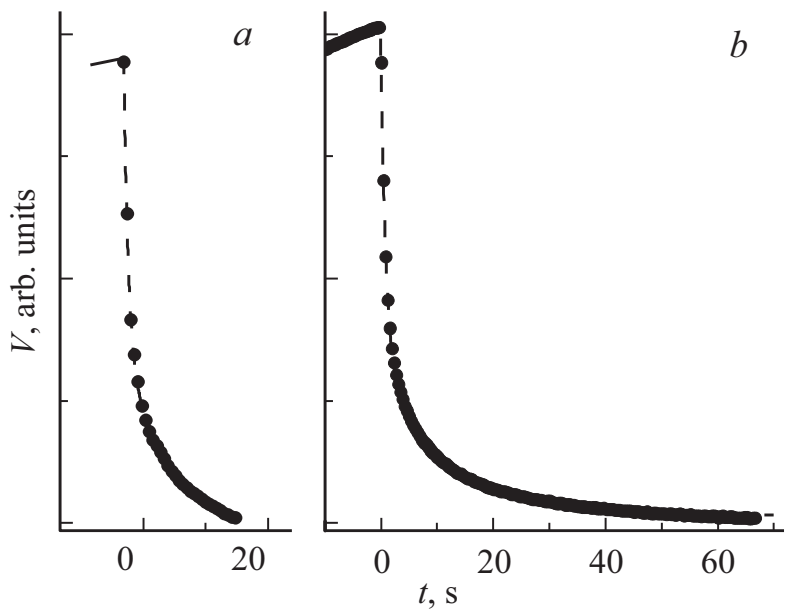

Рис. 8. Кинетические кривые затухания фотоэдс ячейки $\mathrm{Au} / \mathrm{CuPc} / \mathrm{NN}-\mathrm{BDPTCDI} / \mathrm{Al}$ - $(a)$ и $\mathrm{Au} / \mathrm{CuPc} / \mathrm{PTCDA} / \mathrm{Al}(b)$, полученные в вентильном режиме при импульсном световом возбуждении. На вставке - схематическое изображение ячейки $\mathrm{Au} / \mathrm{CuPc} / \mathrm{NN}-\mathrm{BDPTCDI} / \mathrm{Al}$.

различия значений энергий НОМО (highest occupied molecular orbital) и LUMO (lowest unoccupied molecular orbital) молекул CuPc и N, N-DBPTCDI [19] следует ожидать, что на интерфейсе $\mathrm{CuPc} / \mathrm{N}, \mathrm{N}-\mathrm{DBPTCDI}$ возможно эффективное пространственное разделение экситонов на свободные электрон и дырку и возникновение фотоэдс до $0.5 \mathrm{eV}$. На рис. 8 приведены кинетические кривые вентильной фотоэдс фотовольтаических ячеек $\mathrm{Au} / \mathrm{CuPc} / \mathrm{NN}-\mathrm{BDPTCDI} / \mathrm{Al}$ и $\mathrm{Au} / \mathrm{CuPc} / \mathrm{PTCDA} / \mathrm{Al}$, полученные при импульсном световом возбуждении. Для ячейки $\mathrm{Au} / \mathrm{CuPc} / \mathrm{NN}-\mathrm{BDPTCDI} / \mathrm{Al}$ кинетическая кривая характеризуется меньшим значением времени затухания. В исследованных структурах в вентильном режиме напряженность электрического поля $(E)$ в слое органического гетероперехода определяется контактной разностью потенциалов между электродами порядка $1 \mathrm{~V}$ и толщиной пленки $(D)$, равной $3 \mu \mathrm{m})$. Эффективную подвижность определяли как $\mu=E D / \tau$, где $\tau-$ время спада фотоэдс в асимптоту. $\tau$ оценивали путем аппроксимации кинетической кривой экспоненциальной зависимостью (рис. 8). Кинетические кривые на рис. 8 достаточно хорошо можно аппроксимировать суперпозицией двух экспонент с постоянной времени $\tau_{1}$ и $\tau_{2}$. Наличие двух компонент обусловлено, вероятно, наличием электронного компонента и более медленного дырочного компонента фототока. Полученные значе-

Значения $\tau$ и $\mu$ исследованных фотовольтаических ячеек $\mathrm{Au} / \mathrm{CuPc} / \mathrm{NN}-\mathrm{BDPTCDI} / \mathrm{Al}$ и $\mathrm{Au} / \mathrm{CuPc} / \mathrm{PTCDA} / \mathrm{Al}$

\begin{tabular}{c|c|c|c|c}
\hline Тип ячейки & $\tau_{1}, \mathrm{~s}$ & $\mu_{1}, \mathrm{~cm}^{2} / \mathrm{V} \cdot \mathrm{s}$ & $\tau_{2}, \mathrm{~s}$ & $\mu_{2}, \mathrm{~cm}^{2} / \mathrm{V} \cdot \mathrm{s}$ \\
\hline $\mathrm{CuPc} / \mathrm{NN}-\mathrm{BDPTCDI}$ & 0.7 & $1.29 \cdot 10^{-7}$ & 6.7 & $7.69 \cdot 10^{-8}$ \\
\hline $\mathrm{CuPc/PTCDA}$ & 1.4 & $0.64 \cdot 10^{-7}$ & 11.5 & $0.78 \cdot 10^{-8}$
\end{tabular}

ния $\tau_{1,2}$ и $\mu_{1,2}$ для ячеек $\mathrm{Au} / \mathrm{CuPc} / \mathrm{NN}-\mathrm{BDPTCDI} / \mathrm{Al}$ и $\mathrm{Au} / \mathrm{CuPc} / \mathrm{PTCDA} / \mathrm{Al}$ сведены в таблицу. Полученные значения подвижности меньше значений подвижности, полученных времяпролетным методом [9] и методом полевого транзистора $[24,25]$, что может быть обусловлено спецификой проведения измерений в воздушной среде [25].

\section{4. Заключение}

Методом АСМ исследована морфология пленок органических полупроводников PTCDA и N, N-DBPTCDI, сформированных вакуумным термическим напылением. Показано, что отжиг пленок при $420 \mathrm{~K}$ приводит к перестройке их структуры и кристаллизации. Показано, что структура спектров оптического поглощения исследованных пленок идентична с учетом батохромного сдвига для N, N-DBPTCDI на $0.1 \mathrm{eV}$. На основе спектров оптического поглощения дана оценка оптической ширины запрещенной зоны пленок PTCDA $\left(E_{g}=2.04 \mathrm{eV}\right)$ и NN-DBPTCDI $\left(E_{g}=1.98 \mathrm{eV}\right)$. Определена температурная зависимость темновой проводимости пленок PTCDA и N, N-DBPTCDI до и после отжига $(T=420 \mathrm{~K})$. Получены значения энергии активации ловушек носителей заряда для PTCDA $\left(E_{a}=0.36 \mathrm{eV}\right.$, а после отжига $\left.E_{a}=0.26 \mathrm{eV}\right)$ и N, N-DBPTCDI $\left(E_{a}=0.35 \mathrm{eV}\right.$, а после отжига $\left.E_{a}=0.12 \mathrm{eV}\right)$. Измерены спектры фотопроводимости исследуемых пленок в режиме постоянного фототока в области края полосы поглощения. Смоделирована структура плотности локализованных в запрещенной зоне электронных состояний. Показано наличие выраженного максимума плотности локализованных состояний в пленке PTCDA в области $0.8 \mathrm{eV}$ от края запрещенной зоны. Для пленки N, N-DBPTCDI такой максимум плотности локализованных состояний отсутствует. В структурах на основе PTCDA/CuPc и $\mathrm{N}, \mathrm{N}-\mathrm{DBPTCDI} / \mathrm{CuPc}$ измерены кинетические зависимости затухания вентильной фотоэдс при импульсном световом возбуждении. Затухание фотоэдс описывается двумя экспоненциальными компонентами. Эффективные значения дрейфовой подвижности носителей заряда лежат составляют $10^{-7}-10^{-8} \mathrm{~cm}^{2} / \mathrm{V} \cdot \mathrm{sec}$.

\section{Финансирование работы}

Работа выполнена при финансовой поддержке Министерства науки и образования РФ (проект № FSGU-2020-0003). Диагностика атомного состава пленок выполнена при поддержке гранта РФФИ (20-03-00026). В работе использовали оборудование ресурсного центра „Физические методы исследования поверхности“ Научного парка СПбГУ.

\section{Конфликт интересов}

Авторы заявляют об отсутствии у них конфликта интересов. 


\section{Список литературы}

[1] B.A. Jones, A. Facchetti, M.R. Wasielewski, T.J. Marks. J. Am. Chem. Soc. 129, 15259 (2007).

[2] H. Bronstein, C.B. Nielsen, B.C. Schroeder, I. McCulloch. Nature Rev. Chem. 4, 66 (2020).

[3] A.N. Aleshin, P.S. Krylov, A.S. Berestennikov, I.P. Shcherbakov, V.N. Petrov, V.V. Kondratiev, S.N. Eliseeva. Synth. Met. 217, 7 (2016).

[4] И.А. Аверин, А.А. Карманов, В.А. Мошников, И.А. Пронин, С.Е. Игошина, А.П. Сигаев, Е.И. Теруков. ФТТ 57, 2304 (2015).

[5] А.С. Комолов, Э.Ф. Лазнева, Н.Б. Герасимова, Ю.А. Панина, А.В. Барамыгин, Г.Д. Зашихин, С.А. Пшеничнюк. ФТТ 58, 367 (2016).

[6] А.С. Комолов, Э.Ф. Лазнева, Н.Б. Герасимова, В.С. Соболев, С.А. Пшеничнюк, Н.Л. Асфандиаров, В.А. Крайкин, B. Handke. ФTT 63, 299 (2021).

[7] A.S. Komolov, E.F. Lazneva, N.B. Gerasimova, Yu.A. Panina, V.S. Sobolev, A.V. Koroleva, S.A. Pshenichnyuk, N.L. Asfandiarov, A. Modelli, B. Handke, O.V. Borshchev, S.A. Ponomarenko. J. Electron Spectr. Rel. Phenom. 235, 40 (2019).

[8] A.Yu. Sosorev, M.K. Nuraliev, E.V. Feldman, D.R. Maslennikov, O.V. Borshchev, M.S. Skorotetcky, N.M. Surin, M.S. Kazantsev, S.A. Ponomarenko, D.Yu. Paraschuk. Phys. Chem. Chem. Phys. 21, 11578 (2019).

[9] S. Vajiravelu, L. Ramunas, G.J. Vidas, G. Valentas, J. Vygintasc, S. Valiyaveettil. J. Mater. Chem. 19, 4268 (2009).

[10] Y.H. Zhou, Z.F. Yang, W.C. Wu, H.J. Xia, S.P. Wen, W.J. Tian. Chin. Phys. 16, 2136 (2007).

[11] M. Scholz, R. Schmidt, S. Krause, A. Schöll, F. Reinert, F. Würthner. Appl. Phys. A 95, 285 (2009).

[12] S. Günes, H. Neugebauer, N.S. Sariciftci. Chem. Rev. 107, 1324 (2007).

[13] A.S. Komolov, Y.M. Zhukov, E.F. Lazneva, A.N. Aleshin, S.A. Pshenichnyuk, N.B. Gerasimova, Yu.A. Panina, G.D. Zashikhin, A.V. Baramygin. Mater. Des. 113, 319 (2017).

[14] M. Vanechek, J. Kochka. Solid State Commun. 39, 1199 (1981).

[15] V. Bulovic, P.E. Burrows, S.R. Forrest, J.A. Cronin, M.E. Thompson. Chem. Phys. 210, 1 (1996).

[16] R.A. Street, K.W. Song, J.E. Northrup. Phys. Rev. B 83, 165207 (2011).

[17] J. Tauc. Phys. Status Solidi 15, 627 (1996).

[18] H. Yoshida. J. Electron. Spectr. Rel. Phen. 204, 116 (2015).

[19] S. Park, T.U. Kampen, D.R.T. Zahn. Appl. Phys. Lett. 79, 4124 (2001).

[20] H. Bassler, A. Kohler. Top. Curr. Chem. 312, 1 (2012).

[21] В.В. Малов, А.Г. Казанский, М.В. Хенкин, А.Р. Тамеев. ПЖТФ 40, 22 (2014).

[22] В.А. Лигачев, В.А. Филиков. ФТП 25, 133, (1991).

[23] L.J.A. Koster, M. Kemerink, M.M. Wienk, K. Maturova, R.A.J. Janssen. Adv. Mater. 23, 1670 (2011).

[24] V. Rani, A. Sharma, P. Kumar, B. Singh, S. Ghosh. Royal Soc. Chem. Adv. 7, 54911 (2017).

[25] K. Yamada, J. Takeya, T. Takenobu, Y. Iwasa. Appl. Phys. Lett. 92, 253311 (2008).

Редактор К.В. Емщев 